1 Mestre em Letras pela Universidade Federal do Paraná (UFPR), com ênfase em Literatura e outras linguagens. Doutoranda do programa de Pósgraduação em Letras da Universidade Federal do
Paraná (UFPR). Roteirista e autora de livros infantis. http://orcid.org/0000-0001-6638-51 E-mail: kurassacarol@gmail.com

Recebido em: 4/3/2019. Aprovado em: 31/5/2019.

Endereço:

Rua XV de Nove

\section{Concepção e desmoronamento da imagem paterna no livro Quando meu pai se encontrou com o ET fazia um dia quente, de Lourenço Mutarelli}

\author{
Conception and collapse of the paternal image in the book \\ When my father met the ET it was a hot day, by Lourenço Mutarelli
}

Caroline Aparecida dos Santos Fernandes ${ }^{1}$ Universidade Federal do Paraná, Programa de Pós-Graduação em Letras, Curitiba, PR, Brasil.

\section{RESUMO}

Lourenço Mutarelli é um autor que transita entre os gêneros e mesmo entre a linguagem verbal e pictórica. Em seu livro Quando meu pai se encontrou com o ET fazia um dia quente (2011), Mutarelli escapa dos quadrinhos que o consagraram e apresenta um livro "memória" cheio de "falsas" fotografias que conta sobre um tempo passado e irreal. Nesse falseamento da lembrança, encontramos uma insistente reprodução da figura paterna. 0 pai é repetido e distorcido nas imagens do livro, imagens desencontradas, borradas e inconsistentes como uma falsa recordação de um encontro alienígena. A repetição da figura paterna proclama um desejo de rememoração e fixação de sua materialidade, ou seja, o artista busca conservar e isolar essa imagem do lugar e do tempo de sua "real" aparição (BERGER, 1982). Nesse procedimento, o trabalho de Mutarelli dialoga com a especificidade da imagem enquanto memória e receptáculo do anseio por permanência e negação da morte. Partindo desses pressupostos, pretende-se verificar como se dá a construção desse personagem no desenvolvimento da obra e como ela evoca o processo essencial da temporalidade da imagem, que só possui realidade na medida em que remete para conhecimentos e valores previamente adquiridos, ou seja, rememorados (FRANCASTEL, 1998).

Palavras-chave: Imagem. Memória. Quadrinhos. Fotografia. Pai.

ABSTRACT

Lourenço Mutarelli is an author who transits between the genres and even between the verbal and pictorial language. In his book Quando meu pai se encontrou com o ET fazia um dia quente (2011), Mutarelli escapes from the comics that consecrated him and presents a "memory" book full of "false" photographs that tells about a past and unreal time. In this memory's distortion we find an insistent reproduction of the paternal figure. The father is repeated and distorted in the pictures of the book, images are mismatched, blurred and inconsistent as a fake reminder of an alien encounter. In the illustrations, an "imperfect" repetition of the paternal figure proclaims a desire for remembrance and fixation of its materiality, that is, the artist seeks to preserve and isolate this image from the place and from the time of its "real" apparition (BERGER, 1982). In this procedure, Mutarelli's work dialogues with the specificity of the image as memory and receptacle of the longing for permanence and denial of death. Based on these assumptions, we intend to verify how the construction of this character takes place in the development of the work and as it evokes the essential process of temporality of the image, which only has reality insofar as it refers to knowledge and values previously acquired, that is, recalled (FRANCASTEL, 1998).

Keywords: Image. Memory. Comics. Photography. Father. 


\section{Introdução}

Nos depoimentos mais recentes de Lourenço Mutarelli é possível verificar seu afastamento da narrativa pictórica e uma gradativa imersão na narrativa verbal. Seu último livro, o filho mais velho de Deus e/ou livro IV (2018), emprega exclusivamente palavras em sua construção. No entanto, são seus trabalhos como quadrinista e suas imagens "degradantes" que mais representam o autor.

Um dos seus últimos trabalhos caracteristicamente pictórico é o livro Quando meu pai se encontrou com o ET fazia um dia quente (2011). Diversa de outros trabalhos, a publicação em questão se localiza em outro lugar, como que vagando entre as produções de quadrinhos do autor e as suas obras estritamente verbais. Com grandes imagens reproduzidas a partir de pinturas com tinta acrílica, o livro é uma proposta distinta, que parece um misto de livro ilustrado e falso álbum de fotografias. Uma produção "estranha" a ponto de problematizar sua classificação e acabar sendo categorizado como história em quadrinhos em sua ficha catalográfica. Sobre a classificação da obra vale, aqui, ressaltar a definição proposta por Sophie Van der Linden para histórias em quadrinhos.

[histórias em quadrinhos] forma de expressão caracterizada não pela presença de quadrinhos e balões, e sim pela articulação de "imagens solidárias". A organização da página corresponde - majoritariamente - a uma disposição compartimentada, isto é, os quadrinhos que se encontram justapostos em vários níveis (LINDEN, 2011, p. 25).

O que poderíamos chamar de imagens solidárias ${ }^{2}$ mal se nota em Quando meu pai se encontrou com o ET fazia um dia quente (2011). Algo que nos lembra imagens solidárias, como descrito por Linden (2011), pode ser verificado na sequência final - que vai da página 97 até a página 104--, mas ainda nos parece questionável, já que a solidariedade é construída página a página e não entre quadros dentro de uma mesma página. 0 mesmo ocorre com os quadros e os balões, sendo os primeiros ausentes e os balões escassos e vazios, em sua maioria.

Serão definidas como solidárias as imagens que, incluídas em uma sequência, apresentam a dupla característica de serem separadas (essa precisão serve para destacar as imagens isoladas que contêm uma profusão de motivos ou anedotas) e serem plásticas e semanticamente sobredeterminadas pelo próprio fato de existirem in praesentia. (T. GROESTEEN, 1999 apud LINDEN 2011, p. 162).

\section{Em busca do pai}

Dentre os diversos elementos instigantes da narrativa de Quando meu pai se encontrou com o ET fazia um dia quente (2011), pretende-se aqui focar a atenção na construção da figura paterna dentro do livro. Principalmente, observando os elementos e artifícios pictóricos, narrativos e fotográficos que constroem o pai ficcional na obra. É importante destacar que este é um estudo inicial de uma pesquisa mais ampla sobre o objeto de estudo.

Para tratar desse pai do livro de Mutarelli, precisamos, primeiramente, visitar o enredo que o acompanha e justifica o seu protagonismo. A obra discorre sobre o encontro do pai com o ET, como o título sugere, porém, esse encontro é apresentado do ponto de vista do filho, a partir de seu olhar sobre o próprio pai. Para contar a história, o filho segue as vias tortuosas da rememoração, desconectando a temporalidade dos eventos que deseja abordar. Esse embaralhamento é justificado na forma narrativa da memória, com fatos que surgem aos poucos para aquele que narra e com falhas de linearidade no enredo. Essa desconexão aparece no texto verbal e é mais acentuada no texto pictórico, fazendo parecer que as ilustrações foram sorteadas a esmo para surgir. Dessa maneira, o filho vai "relembrando" o pai, contando como ele era, seus hobbies de colecionar fotos de desconhecidos e sua mania de tentar consertar coisas sem sucesso, entre outros detalhes. Assim como um pai, o narrador nos apresenta, também, uma mãe. Figura que falece em um acidente, o que, consequentemente, desencadeia o processo de degradação da figura paterna. Durante o processo de luto, o pai é convidado pelo irmão para pescar. Na pescaria ambos observam uma estranha luz no céu. 0 pai escolhe seguir a luz, adentrando o leito seco de um rio. Ele permanece, então, desaparecido por dois dias. Quando é encontrado, conta sobre o ET. O absurdo de sua experiência desencadeia seu confinamento em um asilo, sua degradação final e morte. Depois de anos da morte do pai, esse filho rememora esse evento, em um resgate da figura paterna pela memória.

A decadência do pai se inicia no luto pela esposa. Esse desmoronamento é marcado por dois momentos: o primeiro é o encontro com o ET e o segundo, 
a redenção do pai a uma memória ficcional, que se verifica quando mistura as fotografias de desconhecidos com as da própria família³.

A figura paterna não vem nomeada no livro. Ele é o pai, um personagem amplo e cheio de conteúdo. Por ser "pai", de maneira ampla, a história desse pai parece não se limitar a um indivíduo específico. É possível observar esse aspecto na forma como a imagem do personagem é edificada ao longo do livro. Nas Figuras 1 e 2 observamos o "provável" pai, pois como as imagens não possuem uma correlação direta com o texto verbal que está próximo, a identificação do pai não está livre de dúvida. Ele surge como um homem velho de óculos e chapéu que nos remete, também, ao autor norte americano Willian Burroughs. Essa correlação não é apenas visual, em outros trabalhos do autor é possível observar seu desejo de reproduzir ou homenagear artistas e referências de seu repertório.

Figura 1 - Quando meu pai se encontrou com o ET fazia um dia quente

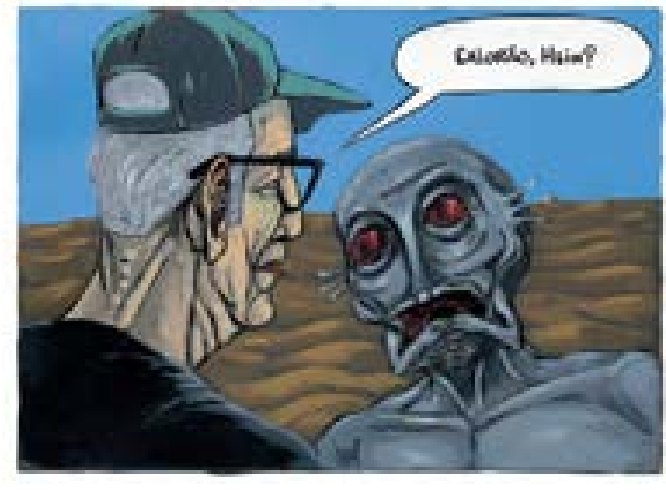

Fonte: Lourenço Mutarelli, 2011, p. 21

Neste artigo usaremos o termo "imaginário", eventualmente, para analisar a construção da figura paterna. Para isso, destacamos aqui o ponto de partida de emprego do termo no estudo. Primeiramente, para Evelyne Patlagean o imaginário constitui um "conjunto das representações que exorbitam do limite colocado pelas constatações da experiência e pelos encadeamentos dedutivos que estas autorizam. Isto é, cada cultura, portanto cada sociedade, e até mesmo cada nível de uma sociedade complexa, tem seu imaginário" (1990, p. 291). Segundo Vilém Flusser, imaginário constitui a ordem da representação do real, um "pensar imagético, representacional e imaginário" diverso do "conceitual, discursivo, crítico" (FLUSSER, 2010, p. 55) que ele atribui a linguagem verbal. 0 imaginário em Lacan surge na forma de um registro essencial da realidade, diverso do ilusório e é, também, "o que tem significação real, o sintoma" (LACAN, 1998, p. 85 apud CHAVES, 2009 , p. 43). Com base nestas reflexões, o imaginário proposto aqui constitui um conceito amplo que envolve um espaço habitado por imagens. Estas, essencialmente, coletivas, nascidas da experiência e concebidas a partir da memória. Imagens que brotam de imagens e ramificam-se em outras diversas.
Figura 2 - Quando meu pai se encontrou com o ET fazia um dia quente

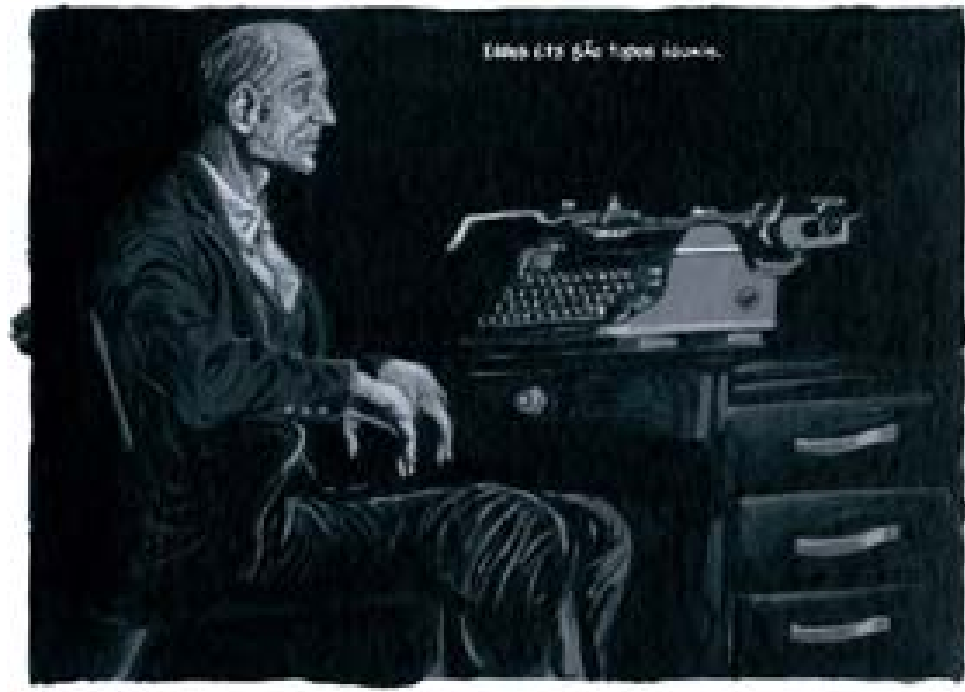

Fonte: Lourenço Mutarelli, 2011, p. 51

No livro $O$ grifo de abdera (2015) é possível encontrar uma autorreflexão do autor sobre sua obra e seus temas, conforme o trecho que destacamos:

Meu editor não entende que eu recorro a um assunto porque ainda não esgotei ele. Ainda estou refletindo sobre isso. Ele falou para eu parar de pôr meu pai nas histórias. [...] E aí você faz o livro do ET com o pai o tempo todo. [...] E o Burroughs também. Eles falaram também pra você não falar mais do maluco (MUTARELLI, 2015, p. 52, grifo nosso).

É necessário destacar que nesse livro o personagem é também escritor e usa como pseudônimo o nome Lourenço Mutarelli. Ali, encontramos o personagem debatendo trabalhos anteriores de Mutarelli como seus e discorrendo sobre seu processo de criação. Observamos que Mutarelli tende a estar presente em seu trabalho, inserindo referências à sua realidade cotidiana e à sua memória individual. 
Mutarelli trabalha constantemente retomando seus temas, como surge na própria fala de seu "eu ficcional" do livro O grifo de abdera (2015). A evocação da figura paterna aparece de diferentes formas e em diversos momentos em sua trajetória4. Em Diomédes (2012) o detetive protagonista é policial, assim como o pai biográfico de Mutarelli (TRIGO, 2015). Em A caixa de areia (2005) o protagonista é Lourenço Mutarelli e a narrativa envolve sua relação com o filho, esposa e também com seu pai, também Mutarelli, e onde já observamos o debate sobre a memória como elemento da ficção do autor. Em seu primeiro romance $O$ cheiro do ralo (2002) o protagonista compra objetos alheios e junto com eles a história que carregam. Uma de suas aquisições é um olho de vidro. A partir do encontro com o olho de vidro, o protagonista constrói uma ficção pessoal, produz uma falsa memória para si. 0 olho não é mais um objeto qualquer, é o olho de vidro do pai do protagonista, pai que foi para uma das guerras. É por meio dessa trajetória que tentamos vislumbrar a construção de um pai ficcional. Um pai desmembrado entre suas obras, assim como o fragmento de pai que o olho de vidro representa em $O$ cheiro do ralo (2002).

Nenhuma outra obra sua demarca tanto o processo de edificação de um pai ficcional como a que propomos debater nesta análise. No livro Quando meu pai se encontrou com o ET fazia um dia quente (2011) a efemeridade da imagem paterna apresenta-se na repetição da imagem desse pai com pequenas variações. Vemos o que parece a mesma "fotografia" em tons, cores e texturas distintas ao longo do livro (Figura 3). No entanto, Mutarelli emprega a linguagem fotográfica de forma distorcida para propor uma imagem ficcional ancorada em um "possível" real, reforçando a concepção de um tipo de imaginário.

4 Meu pai é uma figura central na minha vida. Direta ou indiretamente, ele sempre fez parte do que escrevo. É um assunto que ainda não esgotei mas talvez esteja resolvendo, e a isso, talvez, se deva o fato de ele estar mais evidente em meus últimos livros. (MUTARELLI apud TRIGO, 2015)

Letrônica | Porto Alegre, v. 12, n. 3, jul.-set 2019: e33499
Figura 3 - Quando meu pai se encontrou com o ET fazia um dia quente
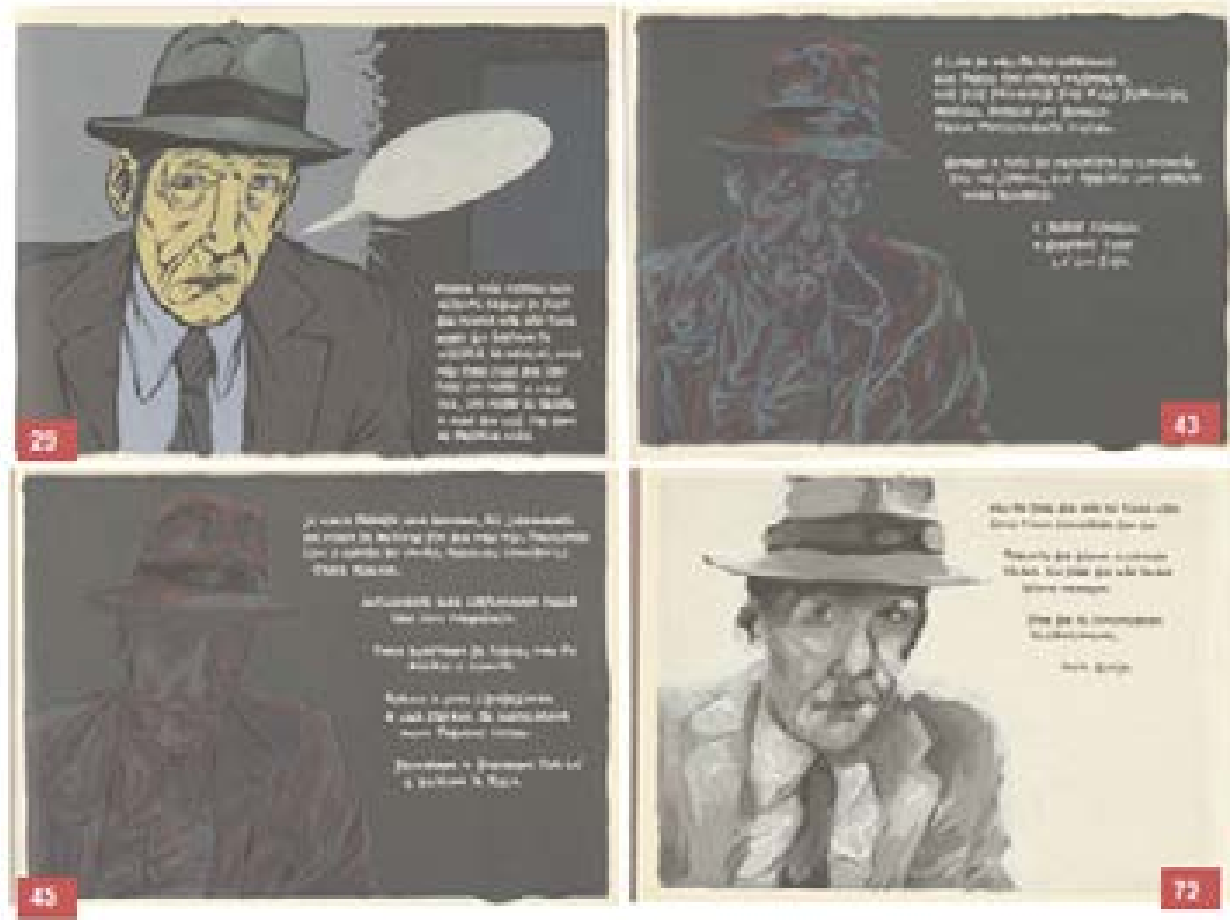

Fonte: Mutarelli, 2011, p. 29; 43; 45; 72

Este procedimento conversa com o modo narrativo proposto por Mutarelli. Modo narrativo que se apresenta em um livro que encena um álbum de família concebido pela lembrança do filho narrador. A partir dos eventos que transmite, o filho tenta resgatar a figura deste pai, busca fixá-la, evocando, desta forma, um conceito de permanência, desejo de fixar o pai no extrato da memória. Isso justifica as repetições e mudanças de cor e texturas. Assim como a tinta, a imagem deste pai está se desprendendo da "tela" da memória do filho, se deteriorando na simulação que a pintura cria e aos poucos parece perder forma. Essa transformação sofrida pela imagem do pai no livro se relaciona com outras reflexões propostas quanto ao conceito de imagem. Uma delas é a apresentada por Etienne Samain. 
Nas reflexões recentes sobre a imagem, vem se desenvolvendo a ideia de que ela alimenta uma relação privilegiada entre o que mostra, o que dá a pensar e o que, sobretudo, se recusa a revelar: o seu próprio trabalho que ela realiza ao se associar, notadamente, a outras imagens (visíveis/ exteriores; mentais/interiores) e outras memórias (SAMAIN, 2012, p. 22).

A imagem carrega em sua essência o desejo de permanência e a apresentação de uma forma de memória. É o que também afirma Georges Didi-Huberman (2013) quando destaca a imagem como um fantasma de outras imagens, anteriores a ela. A repetição da figura do pai que se transforma e se desfaz, é um exercício imagético nascido da memória e que a evoca. Os diversos "pais" em suas variadas composicõos corroboram com a especificidade espectral da imagem, e um imaginário. É o fantasma deste pai "narrado" que se apresenta no livro.

As próprias imagens, nessa óptica de retorno de fantasmas, viriam a ser consideradas como aquilo que sobrevive de uma dinâmica e uma sedimentação antropológicas tornadas parciais, virtuais, por terem sido, em larga medida, destruídas pelo tempo. A imagem [...] deveria ser considerada, portanto, numa primeira aproximação, o que sobrevive de uma população de fantasmas (DIDI-HUBERMAN, 2013, p. 35, grifo do autor).

Inerente ao debate da permanência e da memória verifica-se nas ilustrações do livro a simulação de um registro fotográfico. As ilustrações do livro foram executadas em pintura acrílica e depois impressas pelo processo offset ${ }^{5}$. No entanto, a forma como são apresentadas no livro simulam, em boa parte delas, um registro fotográfico. As falsas fotografias têm o papel de um "como se”, presente nos estudos de Irina Rajewsky (2012), a ilusão de outra mídia concebida nas especificidades da mídia diante de nós, ou seja, parecem fotografias, mas foram criadas por meio da pintura acrílica sobre papel. Os elementos diante de nós, o livro com a reprodução das pinturas em acrílico, "são usados e adaptados de tal modo que eles guardam correspondência e semelhança com elementos" (RAJEWSKY, 2012, p. 61) da reprodução fotográfica. Essa "falsificação" corrobora com a narrativa de memória, a qual transita

Para a análise nos interessa a produção em acrílica das ilustraç̃ões pelo autor, o que simula o processo fotográfico já que a impressão em offset é necessária para garantir a reprodutibilidade do objeto como livro.

Letrônica | Porto Alegre, v. 12, n. 3, jul.-set 2019: e33499 entre algo factual, corriqueiramente relacionado ao registro fotográfico, e a lembrança ficcional, que pode ser uma construção imagética e mental.

Essa simulação nos oferece a impressão de um álbum de fotografias, o que converge com a personalidade do pai, que colecionava fotos de desconhecidos, fotos adquiridas em uma feira de antiguidades (Figura 4). Como mencionado no enredo, quando o pai atinge sua degradação final no abandono do asilo, ele solicita as fotos de família e mistura elas com a coleção de rostos desconhecidos. Conforme o procedimento narrativo apresentado no livro que funde o coletivo e o individual na criação do pai e na história do ET, o pai executa o mesmo processo na consolidação do que deseja recordar.

Figura 4 - Quando meu pai se encontrou com o ET fazia um dia quente

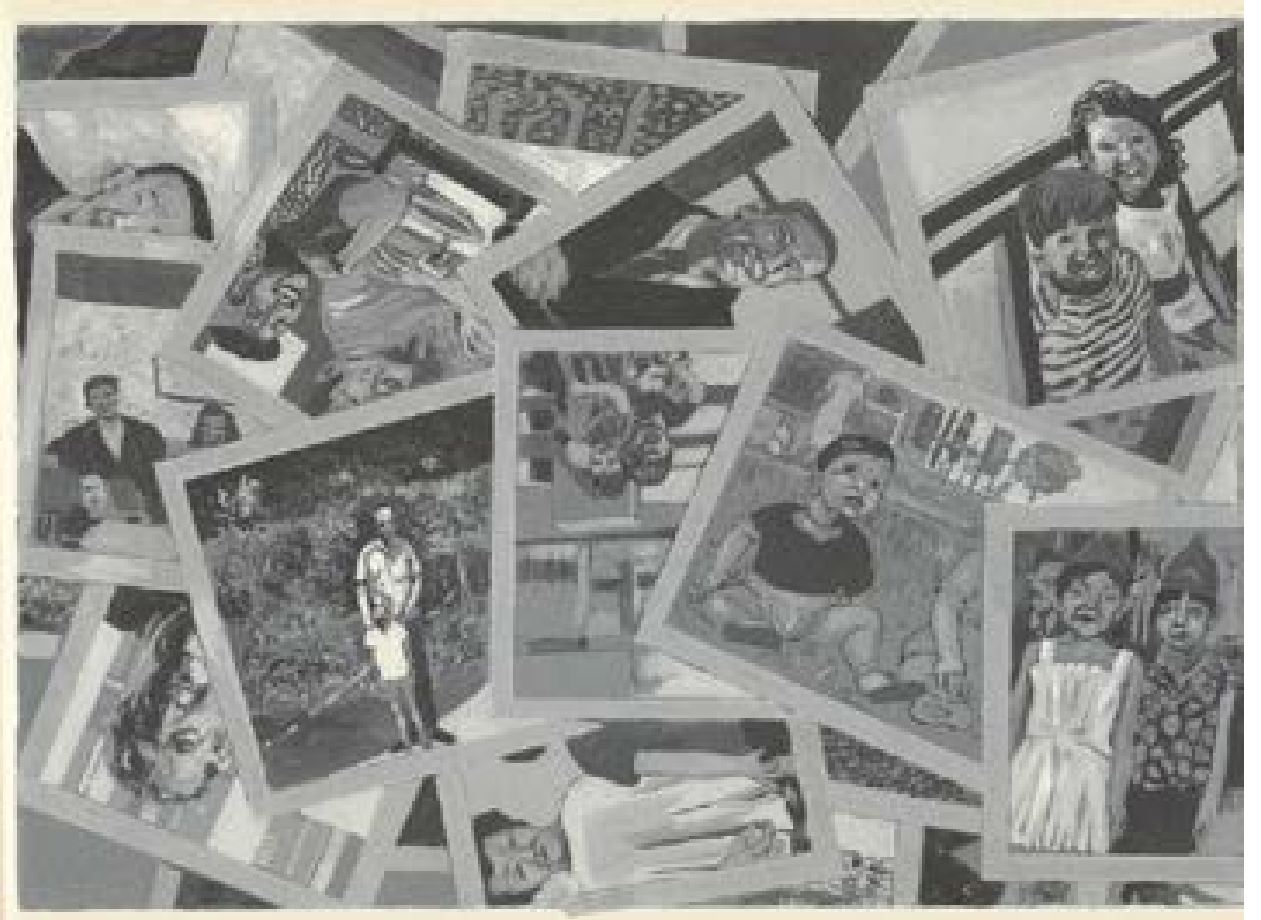

Fonte: Mutarelli, 2011, p. 89. 
A fusão é observada, ainda, na interferência e colagem que surgem nas "fotografias" colecionadas. No decorrer do livro as prováveis fotografias da coleção se repetem, são modificadas e outras vezes incluem novos personagens e elementos. Essa desconstrução retoma a montagem que constitui o próprio ato de recordar, onde elementos surgem fora de lugar e podem se perder no processo. Esse procedimento constrói outra camada de simulação e ficção da memória narrativa.

A falsa fotografia é bem empregada na narrativa, não apenas para apoiar o discurso de memória do filho em busca do pai. Esse artifício converge com o evento absurdo do encontro com o extraterrestre, contrapondo os dois relatos que seguem em paralelo no livro: a existência desse pai e a existência desse ET.

É interessante notar, conforme aparece também na Figura 4, a repetição do retrato do pai. 0 retrato surge em momentos diversos do livro e sempre traz o pai olhando fixamente em nossa direção, para o leitor/expectador. É um olhar que também nos olha, ele questiona. Ele atua como uma exigência, um pedido para que não seja esquecido, um reconhecimento pelo olhar, um pedido de diálogo.

Isso que o rosto expõe e revela, não é qualquer coisa que possa ser formulada nessa ou naquela proposição significante, nem mesmo é um segredo destinado a restar para sempre incomunicável. A revelação do rosto é a revelação da própria linguagem. Essa não tem, consequentemente, nenhum conteúdo real, não diz a verdade sobre esse ou aquele estado da alma ou de fato, sobre esse ou aquele aspecto do homem ou do mundo: é unicamente abertura, unicamente comunicabilidade (AGAMBEN, 1996, p. 74).

Conforme o que afirma Giorgio Agamben sobre a especificidade do rosto, esse é o lugar de exposição do ser, a abertura para a comunicação. Por isso é possível identificar no rosto do pai - que não apenas nos está exposto, mas que também nos olha - um clamor, um pedido. Esse olhar que nos fala, produz um forte contraste com a ausência da narrativa direta do pai. A história é narrada pelo filho, sem uma fala direta do pai sobre sua própria história. Ele surge preso dentro de imagens que vão se deteriorando sem poder expressar sua própria voz. Ele é uma "foto desbotada" de um passado um pouco distante. Por outro lado, o rosto também é todo rosto, "o estar-junto dos múltiplos semblantes que o constituem" (AGAMBEN, 1996, p. 77), ou seja, o rosto em si é também uma memória coletiva, o limiar de desapropriação e de exterioridade, segundo
Agamben. É dessa matéria que é feita a memória narrada no livro de Mutarelli: um diálogo, choque e misto de memória coletiva e memória individual.

Na fictícia caracterização fotográfica que propõe Mutarelli, podemos olhar esse retrato do pai pelo viés da análise fotográfica proposta, ainda, por Agamben. Nela, ele afirma que o indivíduo fotografado que nos observa denota em seu olhar "uma exigência: o sujeito fotografado exige algo de nós. [...] aquela pessoa, aquele rosto exige o seu nome, exigem que não sejam esquecidos" (AGAMBEN, 2007, p. 24).

Quando tratamos de esquecimento estamos refletindo precisamente sobre a memória. É sobre a especificidade do texto recordatório e familiar que se edifica a narrativa de Mutarelli sobre o pai e o ET. Por isso reforçamos o emprego da fotografia ficcional como parte da motivação do discurso e parte intrínseca do sentido da obra. Quando o pai é apresentado no texto verbal como alguém que coleciona memórias alheias por meio das fotografias anônimas, encontramos novo apoio para este sentido. Há na fotografia, por si só, esta relação com a memória: "A imagem fotográfica é sempre mais que uma imagem: é o lugar de um descarte, de um fragmento sublime entre o sensível e o inteligível, entre a cópia e a realidade, entre a lembrança e a esperança" (AGAMBEN, 2007, p. 24). É esse espaço entre a lembrança e a esperança que nos surge no livro Quando meu pai se encontrou com o ET fazia um dia quente (2011). A narrativa se move entre um e outro, entre uma verossímil memória do pai e uma esperança em um evento fantástico, que se configura no encontro com o ET. Da mesma forma, a fotografia aparece como um objeto carregado de obrigação factual e, no entanto, é também ficção.

Da mesma forma que o pai é edificado sobre uma imagem vaga e efêmera, o ET surge em múltiplas formas. 0 ET aparece como possibilidade ficcional e se mostra, pictoricamente, em diferentes formas corpóreas. Cada forma assumida pelo ET dialoga com uma referência coletiva de contato extraterrestre. Ora como pequenos lagartos, outra remetendo a descrição de um chupa-cabras (MUTARELLI, 2011, p. 87) e assim por diante. Nas últimas páginas do livro o que pode ser, também, identificado como um ET vem "buscar" esse pai e levá-lo para dentro do rio seco. Nese momento ele assume a forma de um ser fantasiado com uma cabeça de papel machê. A seleção do último ET é significativa. Não é mais uma referência vaga, ela está contida dentro da narrativa. A criatura "escapa" de uma das fotografias colecionadas por esse pai (MUTARELLI, 2011, p. 41) para ressurgir no término do livro. 
A figura extraterrestre é tão fragmentada quanto a paterna. Ela vai se desmanchando em imagens e palavras. Isso é mais evidente pelo procedimento estilístico presente nas imagens do pai, como na decomposição que aparece na pintura acrílica vista na Figura 3. 0 processo de esquecimento e apagamento do pai pode ser verificado, também, nas palavras do livro. Primeiro, identificamos uma ausência de uma fala direta do pai sobre sua própria história. 0 espaço para essa "fala" está construído na forma de balões, no entanto, a maioria deles está vazia. Há apenas um texto verbal atribuído ao pai dentro dos balões: a fala "calorão, hein?", como pode ser visualizado na Figura 1. Os balões vazios denotam algo que existia e que se apagou: o próprio esquecimento.

0 segundo momento de apagamento da imagem do pai dentro do texto verbal surge na reprodução da fala do pai dentro da narração verbal do filho: "Então como que eles são? [...] "Não dá para descrever. Eles são diferentes de tudo o que se possa imaginar" (MUTARELLI, 2011, p. 74). Nem mesmo quando lhe é dada a fala, o pai consegue expressar sua história. 0 pai é, pouco a pouco, esquecido e vai se perdendo dentro de sua própria narrativa, "o esquecimento se relaciona com o conceito de rastro, pelo apagamento. Se somos incapazes de nos lembrar de tudo, somos ainda mais incapazes de tudo narrar" (RICOEUR, 2003, p. 7). O livro é composto desses rastros deixados pelo pai, marcas e sinais de sua passagem que vão perdendo nitidez. Por este motivo o final do livro é tão carregado de significado.

Quando viu a luz no céu, o pai seguiu o suposto disco voador pelo leito seco de um rio (MUTARELLI, 2011, p. 47). Nas ilustrações, este leito seco aparece como um deserto, um monte de areia (Figura 5). Na sequência que vai da página 97 até a página 104 observamos o pai seguindo uma estranha figura por esse leito até se perder na distância. Nenhum texto verbal acompanha esta sequência. No intervalo destas páginas é possível verificar uma provável relação solidária entre as imagens como apontada por Linden (2011). Porém, não é algo que lembre as imagens solidárias das histórias em quadrinhos, principalmente porque a progressão temporal se dá no virar das páginas e não em uma mesma página, como costumamos observar nos quadrinhos ${ }^{6}$.

6 Esse modelo de continuidade surge frequentemente em livros ilustrados. No entanto, é importante reforçar que a linguagem dos quadrinhos não se limita a quadros, balões e imagens solidárias e pode, sim fugir disso. Trabalhos experimentais como Breakdowns (2009), de Art Spiegelman, ou ainda o recente Aqui (2017), de Richard McGuire, são importantes exemplos neste sentido.
Figura 5 - Quando meu pai se encontrou com o ET fazia um dia quente

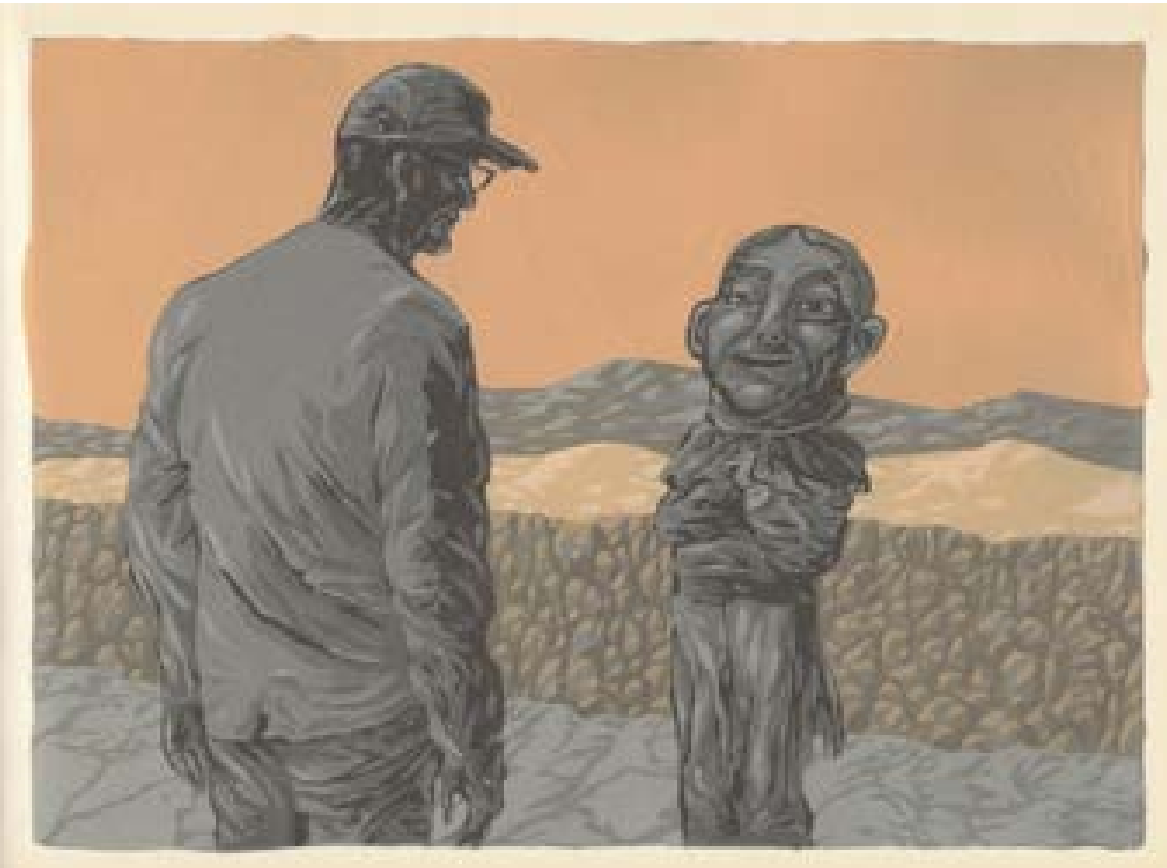

Fonte: Mutarelli, 2011, p. 97.

É notável, neste ponto final da narrativa, o desaparecimento do pai. Ele vai se perdendo, partindo, enquanto adentra o espaço vazio amplo do leito seco do rio. 0 livro termina com o pai ao lado da criatura, menor em relação às páginas anteriores, avançando para dentro deste espaço (MUTARELLI, 2011, p. 100). Depois, observamos uma sequência de três páginas que mostra apenas o leito seco do rio, inabitado. Na última página, que também mostra o leito seco, lemos a seguinte frase: "vamos em frente" (MUTARELLI, 2011, p. 104). Essa ordem verbal que brota do silêncio das últimas páginas parece enfatizar o esquecimento, o pai ficou para trás, perdido nesse espaço vazio, partiu sem deixar muitos rastros na terra seca do rio. 
Esse espaço desértico não é novo na trajetória de Mutarelli. Seu livro A caixa de areia (2005) traz uma imagem semelhante à do leito seco do rio (Figura 6), porém, ali o vazio é de areia, o que não deixa de estar próximo da terra e da areia que permanece quando o rio seca. Nessa areia ou terra molhada resta apenas o rastro da existência do pai. Esses rastros podem ser percebidos nas "fotografias" desgastadas e no retrato desse pai que vai perdendo forma ao longo da narrativa. Alguns dos rastros foram apagados, como as falas que deveriam surgir dentro dos balões (MUTARELLI, 2011, p. 29).

Figura 6 - A caixa de areia

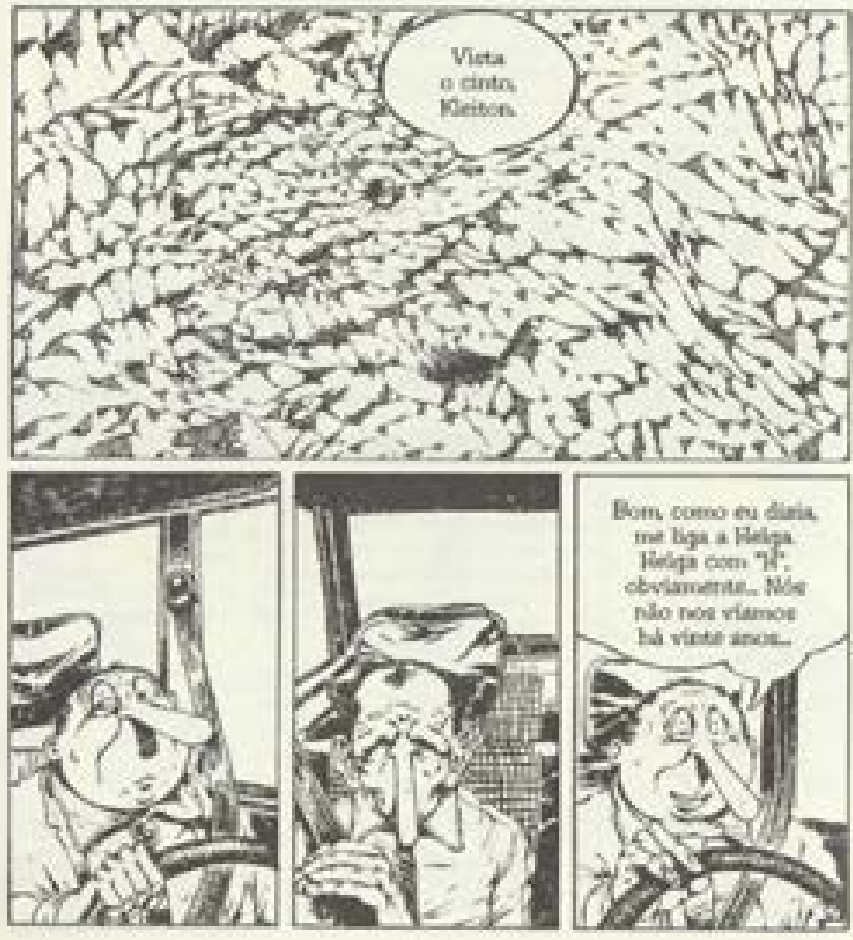

IIs

Fonte: Mutarelli, 2005, p. 118.
A imagem do pai tenta permanecer nesses rastros, como peças de um quebracabeça feito das lembranças do filho. Jeanne Marie Gagnebin (2006) fala dos rastros como metáforas da memória em um de seus artigos. Nele, decompõe o rastro também em sucata, lixo e detrito, assim como destaca que o rastro segue um caminho distinto do signo linguístico, pois aparece sem intenção de significar. Assim, os rastros do pai nos remetem à fala, já trazida aqui, de Agamben sobre a fotografia: "é o lugar de um descarte, de um fragmento sublime entre o sensível e o inteligível" (AGAMBEN, 2007, p. 24). São as sobras da memória, dos fragmentos do pai que se espalham de forma embaralhada no livro de Mutarelli. Essa efemeridade do ser "pai" é expressa na repetição de seu rosto atento e observador, mas que parece se desmanchar pouco a pouco diante de nós. Segundo Emmanuel Levinas:

o rastro tem ainda isto de excepcional em relação a outros signos: ele significa fora de toda intenção de significar [...] Ele decompôs a ordem de forma irreparável. Pois ele passou absolutamente. Ser, na modalidade de deixar um vestígio, é passar, partir, absolver-se (LEVINAS,1993 apud GAGNEBIN, 2006, p. 113).

Encontramos a imagem do pai arquitetada como um vestígio de memória. 0 pai surge como um imaginário próprio do autor e ancorado em seu repertório. São fragmentos perdidos no texto verbal não dito, no olhar do pai que vai ficando borrado e nas fotografias de desconhecidos. A imagem do pai é construída e perdida dentro de uma memória mais ampla, um imaginário que resgata Burroughs, retratos anônimos e contatos de terceiro grau.

Nesse procedimento verificamos, novamente, o embaralhamento entre as diversas memórias do livro, conforme o mesmo procedimento do pai, que embaralha as fotos de família com as fotos anônimas no asilo, abandonando sua memória individual para abraçar uma memória coletiva, uma ficção mais ampla, para talvez ser parte de uma memória também mais ampla.

Uma imagem, toda imagem, resulta dos movimentos provisoriamente sedimentados ou cristalizados nela. Esses movimentos a atravessam de fora a fora, e cada qual tem uma trajetória - histórica, antropológica, psicológica - que parte de longe e continua além dela. [...] ficamos diante da imagem como diante de um tempo complexo, o tempo provisoriamente figurado, dinâmico, desses próprios movimentos (DIDI-HUBERMAN, 2013, p. 33-34). 
O livro Quando meu pai se encontrou com o ET fazia um dia quente (2011) propõe essa trajetória e a modela de diversas formas. A imagem do pai é atravessada por discursos históricos, antropológicos e psicológicos, como vimos no decorrer da análise. 0 tempo atravessa a imagem do pai, trazendo consigo as demais obras de Mutarelli em seu encalço, resgatando as referências do autor e recorrendo ao modo recordatório de expressão. É por meio da memória que se dá a narrativa e a edificação das imagens. 0 processo de lembrar ordena o discurso e desconstrói, quando necessário, a mensagem.

\section{Considerações finais}

Observando sua trajetória e as demarcações visíveis no livro Quando meu pai se encontrou com o ET fazia um dia quente (2011), podemos afirmar que a figura paterna dialoga com uma memória pessoal, que evoca o pai biográfico do autor, e, ao mesmo tempo, conversa com uma memória coletiva e ampla que traz à tona o repertório e as referências do autor. 0 imaginário criado ali é pictoricamente verificado na relação com Burroughs, com a impressão da imagem deste pai e com sua caracterização aberta: ele é o pai, todos os pais e não um pai específico. Ou seja, o pai de Mutarelli existe dentro da ficção alimentado por fragmentos "reais" e ficcionais da parentalidade da vida do autor.

Por caminhos diversos, Mutarelli constrói o esquecimento do pai. São diversos os rastros e fragmentos do esquecimento. Eles se somam nesta edificação de uma narrativa de memória um tanto vaga. Podemos verificar o esquecimento, essencialmente, na figura paterna que segue implorando por permanência no decorrer de imagens desconexas que se deterioram pouco a pouco. Sua voz é ausente e ele se torna quase tão improvável quanto o próprio ET.

Por tudo isso, pegamo-nos olhando para a obra como um experimento de memória e um álbum de família distorcido, onde o discurso é impregnado de vazios e ausências próprias do esquecimento. 0 narrador busca o pai nas fotos, na lembrança e na narrativa de sua deterioração. Porém, acaba por perdêlo irremediavelmente no final. 0 pai é um vestígio, um rastro do momento passado, que vaga, fragmentado, na existência do filho.

\section{Referências}

AGAMBEN, Giorgio. O rosto. In: AGAMBEN, Giorgio. Mezzi senza fine: Note sulla politica. Tradução Murilo Duarte Costa Corrêa. Torino: Bollati Boringhieri, 1996. p. 74-80.

AGAMBEN, Giorgio. Profanações. Tradução e apresentação de Selvino José Assmann. São Paulo: Boitempo, 2007.

BERGER, John. Modos de ver. São Paulo: Martins Fontes, 1982.

CHAVES, Wilson Camilo. Considerações a respeito do conceito de real em Lacan. Revista Psicologia em Estudo, Maringá, v. 14, n. 1, p. 41-46, jan./mar. 2009. Disponível em: http://www. scielo.br/pdf/pe/v14n1/a06v14n1.pdf. Acesso em: 20 fev. 2019. https://doi.org/10.1590/s141373722009000100006

DIDI-HUBERMAN, Georges. A imagem sobrevivente: história da arte e tempo dos fantasmas segundo Aby Warburg. Trad. Vera Ribeiro. Rio de Janeiro: Contraponto, 2013.

PATLAGEAN, Evelyne. A história do imaginário. In: LE GOFF. A nova história. Trad. Eduardo Brandão. São Paulo: Martins Fontes, 1990. p. 291-318.

FRANCASTEL, Pierre. A imagem, a visão e a imaginação. Trad. Fernando Caetano. Lisboa: Edições 70, 1998.

FLUSSER, Vilém. A escrita: Há futuro para a escrita? Trad. Murilo Jardelino da Costa. São Paulo: Annablume, 2010.

GAGNEBIN, Jeanne Marie. Lembrar escrever esquecer. São Paulo: Ed. 34, 2006.

LINDEN, Sophie Van der. Para ler o livro ilustrado. São Paulo: Cosac Naify, 2011.

MCGUIRE, Richard. Aqui. Tradução Érico Assis. 1. ed. São Paulo: Quadrinhos na Cia, 2017

MUTARELLI, Lourenço. Quando meu pai se encontrou com o ET fazia um dia quente. São Paulo: Companhia das Letras, 2011.

MUTARELLI, Lourenço. A caixa de areia. São Paulo: Companhia das Letras, 2005.

MUTARELLI, Lourenço. Diomédes: a trilogia do acidente, edição completa. São Paulo: Companhia das Letras, 2012.

MUTARELLI, Lourenço. O cheiro do ralo. São Paulo: Companhia das Letras, 2002. 
MUTARELLI, Lourenço et al. O grifo de Abdera. São Paulo: Companhia das Letras, 2015.

SAMAIN, Etienne. Como pensam as imagens. In: SAMAIN, Etienne (org.). Como pensam as imagens. Campinas, SP: Editora Unicamp, 2012. https://doi.org/10.7476/9788526814738

SPIEGELMAN, Art. Breakdowns: retrato do artista quando jovem \%@. Tradução Vanessa Bárbara. São Paulo: Companhia das Letras, 2009.

RAJEWSKY, Irina O. Intermidialidade, intertextualidade e 'remediação'. In: DINIZ, Thaïs Flores Nogueira (org.). Intermidialidade e estudos Interartes: desafios da arte contemporânea. Belo Horizonte: Editora UFMG, 2012.

RICOEUR, Paul. Memória, história e esquecimento. Conferência foi escrita e proferida em inglês por Paul Ricoeur a 8 de março de 2003 em Budapeste sob o título "Memory, history, oblivion" no âmbito de uma conferência internacional intitulada "Haunting Memories? History in Europe after Authoritarianism". Disponível em: http://www.uc.pt/fluc/uidief/textos ricoeur/ memoria historia . Acesso em: 09 jan. 2018. https://doi.org/10.15848/hh.v0i19.897

TRIGO, Luciano. Lourenço Mutarelli: meu pai é uma figura central na minha vida. Portal G1. Publicado em 15/11/2015. Disponível em: http://g1.globo.com/pop-arte/blog/maquina-deescrever/post/lourenco-mutarelli-meu-pai-e-uma-figura-central-na-minha-vida.html. Acesso em: 10 maio 2018. https://doi.org/10.26512/2016.03.d.20845 